\title{
Renewable Energy Promotion in South Africa - Surrounding Conditions and Recent Developments
}

\author{
By Cord Lüdemann, Stellenbosch*
}

\section{A. Introduction}

The field of renewable energies has registered a substantial growth in the last two decades. Over the two-year period from 2008 to 2009, 140 Giga Watts (GW) were added from new renewable energy installations globally, which is nearly half of the approximate $300 \mathrm{GW}$ of new electricity generating capacity in total. ${ }^{1}$ These growth rates also result from an increasing understanding of the necessity for policy instruments to promote renewable energies. The necessities and conflicts connected with the deployment of renewable energy technologies are universal and often crucial when it comes to renewable energies in developing countries. The following article draws attention to the South African promotion policy. The South African case features typical challenges of an emerging economy including heavy reliance on fossil fuels with high emission rates, high requirements with regard to energy access and the problem of energy poverty. This article aims at familiarising with the South African measures on renewable energy promotion. In a second step the South African measures will be put in the broader context of renewable support policies, climate change and socio-economic development needs.

\section{B. Regulatory framework conditions in South Africa}

Unlike the promotion of renewable energies in other countries, the South African regulatory framework lacks an umbrella statute comprehensively dealing with the promotion of renewable energies. Nevertheless, reference to renewable energies and their promotion is made in several policy documents and the National Energy Act 34 of $2008 .^{2}$ In addition administrative measures have been introduced to support renewable energies. First step in this context was the Renewable Energy Feed-in Tariffs (REFIT) announced by the National Energy Regulator for South Africa (NERSA) in 2009. In a recent policy change, the government has been setting

* Cord Lüdemann has previously worked for the Energy Department at the German Federal Network Agency (Bundesnetzagentur). He has recently finished his LLM studies and is now LLD Candidate at the Faculty of Law, Stellenbosch University. E-mail: cluedemann@sun.ac.za

This article is derived from a longer research paper supervised by Professor Oliver C Ruppel. All views expressed in this article are those of the author.

1 IPCC Working Group III, Special Report on Renewable Energy Sources and Climate Change Mitigation (SRREN) - Summary for Policy Makers, 2011, <http://srren.ipcc-wg3.de/report/IPCC_SRREN_SPM $>$ (accessed 24-01-2012), p 6.

2 National Energy Act No. 34 of 2008, Government Gazette No. 31638 (24. November 2008). 
up a procurement programme for renewable energy capacity which has now replaced the earlier NERSA measures.

\section{Policy documents}

The main policy goals and objectives for the energy sector are set out in two White Papers. The 1998 White Paper on Energy Policy of the Republic of South Africa ("1998 White Paper") defines the official policy on the production, distribution and consumption of energy. The policy on renewable energies - outlined in a specific section- seeks to ensure that economically feasible renewable energy technologies are implemented and that an equitable level of national resources is invested in renewable technologies. ${ }^{3}$ Furthermore the document aims at addressing constraints in the development of the renewable energy industry as an important challenge. ${ }^{4}$

This initial commitment to renewable energy technologies was supplemented by a specific policy document on renewable energies. The 2003 White Paper on Renewable Energy ("2003 White Paper") recognises the value of renewable energies for the diversification of energy resources and sets a medium-term target of 10,000 $\mathrm{GWh}$ renewable energy contribution to final energy consumption by $2013 .{ }^{5}$ Furthermore it focuses on the need of creating an enabling environment through the introduction of fiscal and financial support mechanisms within an appropriate legal and regulatory framework. ${ }^{6}$ According to the 2003 White Paper four key strategic areas have to be addressed, namely financial instruments, legal instruments, technology development, and awareness raising, capacity building and education. The legal instruments refer to an appropriate legal and regulatory framework for pricing and tariff structures; this is deemed necessary to support the integration of renewable energy into the energy economy as well as to attract investment in the renewable energy sector. ${ }^{7}$ In this light, the 2003 White Paper aims at achieving full competitiveness of the renewable sector and "to build an energy industry that will offer a fully non-subsidised alternative to fossil fuels." 8

3 South African Department of Minerals and Energy, White Paper on Energy Policy of the Republic of South Africa, 1998, <http://www.energy.gov.za/files/policies/whitepaper_energypolicy_1998.pdf> (accessed 24-01-2012), p. 79.

4 Department of Minerals and Energy, White Paper on Energy Policy of the Republic of South Africa, 1998, p. 79.

5 South African Department of Minerals and Energy, White Paper on Renewable Energy, 2003, $<\mathrm{http}: / /$ www.energy.gov.za/files/policies/whitepaper_renewables_2003.pdf> (accessed 24-01-2012), p. $5+$ 25.

6 South African Department of Minerals and Energy, White Paper on Renewable Energy, 2003, p 5.

7 South African Department of Minerals and Energy, White Paper on Renewable Energy, 2003, p 33.

8 Edson L Meyer/ Kola O Odeku, Climate Change, Energy, and Sustainable Development in South Africa: Developing the African Continent at the Crossroads, Sustainable Development Law \& Policy (2008-2009), p. 51. 


\section{National Energy Act 34 of 2008}

The National Energy Act is a consequence of the previous 2003 White Paper. It contains basic legal provisions concerning energy planning and seeks to ensure that diverse energy resources are available in sustainable quantities and at affordable prices. ${ }^{9}$ The Act also states that it is supposed to provide for energy planning and increased generation and consumption of renewable energies. These preamble words show that the scope of the National Energy Act includes renewable energies. However, in its objectives in section 2, the Act only refers to diversity of supply of energy and its sources in general but not expressly to renewable energies. ${ }^{10}$ Moreover, renewable energies only reflect in one provision of the Act: Section 19 refers to general regulations the Minister may make which include regulations regarding the minimum contributions to national energy supply from renewable energy sources as well as regulations regarding measures and incentives designed to promote the production, consumption, investment, research and development of renewable energy. ${ }^{11}$ This authorisation in section 19 is far-reaching. The minister has the mandate to comprehensively introduce measures in favour of renewable energies. Yet, the aspect is left to the discretion of the minister. No minimum contributions of renewable energies to the national supply mix derive directly from the Act, nor do measures to promote renewable energies. Consequently, and although renewable energies generally fall within its scope, the National Energy Act does not provide legal security for producers and investors in the field of renewable energies. Therefore, the Act cannot be regarded as the appropriate legal framework envisaged by the 2003 White Paper.

\section{Renewable Energy Feed-In Tariff (REFIT)}

In 2009, NERSA published its REFIT decisions accompanied by regulatory guidelines on the REFIT system. ${ }^{12}$ Main achievements of this system were concrete tariffs which guaranteed purchase prices for a fixed period of time. According to the NERSA guidelines, tariffs were supposed to cover the costs of generation plus a reasonable return on investment to attract developers and investors. ${ }^{13}$ They had to be calculated for each single renewable energy technology as both the cost structures as well as the investment environment vary across the different technologies. The initial tariff system adopted in March 2009 included four tech-

9 Preamble, National Energy Act.

10 Section 2 (b) National Energy Act.

11 Section 19 (d), (f) National Energy Act.

12 The NERSA decisions are published on the NERSA homepage http://www.nersa.org.za/ under Regulator decisions/Electricity/Reasons for Decisions on Renewable Energy Feed-in Tariffs (REFITs) Phase II, 30 October 2009 + Reasons for Decision on the Renewable Energy Feed-In Tariff (REFIT) (accessed 24-01-2012).

13 NERSA, South Africa Renewable Energy Feed-in Tariff (REFIT) - Regulatory Guidelines 26 March 2009, Notice 382 of 2009, Government Gazette 32122, <http://greengazette.co.za/documents/national-gazette-32122-of-17-apr-2009-vol-526_20090417-GGN-32122.pdf> (accessed 24-01-2012), p. 11 (of the Gazette). 
nologies (on-shore wind, small hydro, landfill gas and concentrating solar power). In a REFIT phase 2 decision in October 2009 further qualifying technologies were introduced, including, amongst others, solid biomass, biogas and solar photovoltaic systems. ${ }^{14}$ In addition to tariffs, the NERSA guidelines and decisions contained further regulations supporting the market introduction of renewable energy technologies. National energy monopolist Eskom's Single Buyer Office was appointed as the Renewable Energy Purchasing Agency (REPA), which is obliged to purchase the power generated by projects licensed under REFIT. ${ }^{15}$ Additionally, the NERSA guidelines provided for a guarantee for renewable energy generators to get access to the network, be it the distribution or the transmission networks, as appropriate. ${ }^{16}$ Further regulations in the NERSA guidelines include the qualification criteria for renewable energy generators as well as comprehensive monitoring and reporting obligations which apply to the Regulator, the generators and the REPA respectively.

\section{Renewable Energy Independent Power Producer Procurement Programme}

In June 2011, officials of the South African Department of Energy outlined a timetable for a competitive bidding procedure. Since, the Department officially invited interested parties with relevant experience to submit proposals for the finance, construction, operation, and maintenance of renewable energy generation facilities. ${ }^{17}$ The Procurement Programme replaces the REFIT-model introduced by NERSA. While REFIT guaranteed fixed tariffs, the price in the new scheme will be set by the bidding procedure. The Procurement Programme consists of two elements: first, bidders have to meet qualification criteria (including legal, environmental and financial requirements) and, secondly, their bid is evaluated on bid price and economicdevelopment objectives. ${ }^{18}$ These economic-development issues can be crucial when it comes to creating a vivid environment for a domestic industry. They might also play an important role for foreign bidders and their involvement in a future renewables industry in South Africa.

The first phase of the bidding process was completed in December 2011 when 1,415 MW were allocated by announcing successful bidders. In March, the bidding for the second round was closed; the successful bidders will be announced mid-May 2012. The next three phases will take place between May 2012 and August 2013. The detailed bid rules are set out in the Request for Qualification and Proposals which can be downloaded once the prospective bidder has paid a non-refundable fee of $\mathrm{R} 15,000$ and completed a registration form. On successful

14 Describing the process in detail: Neil Van der Merwe, Legislation's role in promoting the acceptance of renewable energy into society, 2009, $<$ http://eepublishers.co.za/images/upload/Legislation_\%20role_in_promoting.pdf $>$ (accessed 24-01-2012), p. 130.

15 NERSA, note 13, p. 32 (of the Gazette).

16 NERSA, note 13, p. 17 (of the Gazette).

17 South African Department of Energy, <http://www.ipp-renewables.co.za/?page_id=52> (accessed 24-01-2012.).

18 Mail \& Guardian online, <http://mg.co.za/article/2011-08-12-a-renewed-focus-on-green-energy> (accessed 24-01-2012.). 
completion of the Procurement Programme the parties will enter, inter alia, an Implementation Agreement with the Department and a Power Purchase Agreement with a buyer. The first experiences with the Procurement Programme give reason to be optimistic. In the second phase, the response adds up to 79 bids covering 3,233 MW of potential renewable energy capacity and thus exceeds by far the 1,275 MW allocated for the March round.

Qualifying technologies under the Procurement Programme are onshore wind, concentrated solar thermal, solar photovoltaic, biomass solid, biogas, landfill gas and small hydro. The overall renewable energy capacity envisaged by the programme amounts to 3,725 MW; the Minister has determined this to be required to ensure the continued uninterrupted supply of electricity. ${ }^{19}$ The capacity shares are attributed by renewable energy technology. By far the largest share is attributed to onshore wind and solar photovoltaic. ${ }^{20}$ The Department's web site for the Procurement Programme promises that the design of the programme will stimulate the renewable industry in South Africa and contribute towards socio-economic and environmentally sustainable growth.

\section{Analysis of the South African measures}

South Africa's recent measures, NERSA's REFIT model and the procurement programme introduced by the Department of Energy represent the two main mechanisms for renewable energy promotion that have emerged in the last two decades. After briefly contrasting these support mechanisms, the South African promotion policy will be put into the broader context of climate change protection efforts and socio-economic framework conditions.

\section{Fixed tariffs versus bidding procedures}

The REFIT system introduced by NERSA was similar to promotion systems introduced, inter alia, by Germany and Spain. These feed-in systems are able to provide future market stability for renewable energy investors, if they are well designed, namely if they include a long-term reach and a sufficient profit margin. ${ }^{21}$ NERSA's decision contained many elements which have proven to be successful in other countries. The crucial challenge in feed-in systems, however, is to set appropriate price signals. If the prices are set too low, the system fails in reducing investment costs. In the absence of favourable investment conditions an increase of renewable energies' market share would be unrealistic. But if prices are set too high, operators of renewable energy plants will obtain windfall profits at the expense of end-users, which

19 South African Department of Energy, http://www.ipp-renewables.co.za/ (accessed 24-01-2012).

20 The envisaged share for onshore wind power amounts to 1,850 MW, with regard to solar photovoltaic the programme envisages 1,450 MW.

21 Joanna Lewis/ Ryan Wiser, Fostering a renewable energy technology industry: An international comparison of wind industry policy support mechanisms, Energy Policy 35 (2007), p. 1854; Mischa Reiche/ Danyel Bechberger, Policy differences in the promotion of renewable energies in the EU member states, Energy Policy 32 (2004) p. 847. 
would constitute an efficiency loss for the economy as a whole. ${ }^{22}$ Hence, feed-in tariffs need to be adjusted carefully considering latest market developments and the technological state of the art. The REFIT system allowed for these adjustments by providing for an annual review of the tariffs for the first five year period of implementation and a review every three years after this period. This model, however, now belongs to the past.

The recently introduced Procurement Programme follows a different approach. The competitive bidding procedure is similar to models that have been performed in the United Kingdom and in several other countries. After defining a reserved market for a given amount of renewable energy, the regulator organises a competition between producers of renewable energy to allocate this amount. ${ }^{23}$ Although competitive bidding procedures seem to have a higher degree of economic efficiency compared to feed in models, past experiences have not proven to create an economically feasible environment. Nor have they supported a wide range of renewable energy resources. So far, bidding procedures could not contribute to long-term market stability or profitability which was partly due to often uncertain or long lead times between tenders as well as the fierce competition among project developers. ${ }^{24} \mathrm{With}$ regard to the specific South African programme, however, the reaction was mixed. While some commentators and project developers criticised the new process and were pessimistic about the outcome, others welcomed the new policy and felt encouraged to invest after long delays and different approaches in South African renewable energy policy in the past. ${ }^{25}$ Promising in this context might be that the bidding process not solely focuses on price. Socio-economic objectives set out by the Department are basis for $30 \%$ of the evaluation criteria. ${ }^{26}$

\section{Renewable energy promotion in light of the current climate change regime}

The need for promotion of renewable energies in many countries results first and foremost from their obligations under the international climate change regime. Renewable energies have not been in the focus of the relevant documents concerning climate change, especially the United Nations Framework Convention on Climate Change (UNFCCC) and the Kyoto Protocol. However, the relevance of renewable energies as mitigation measures is widely recognized nowadays. ${ }^{27}$ In May 2011, the Intergovernmental Panel on Climate Change (IPCC)

22 Marc Ringel, Fostering the use of renewable energies in the European Union: the race between feedin Tariffs and green certificates, Renewable Energy31 (2006) p 7.

23 Phillippe Menanteau/Dominique Finon/Marie-Laure Lamy, Price versus quantities: choosing policies for promoting the development of renewable energy, Energy Policy 31 (2003) p. 802.

24 Joanna Lewis/Ryan Wiser, note 21, p. 1854.

25 Mail \& Guardian online, Note 18.

26 Mail \& Guardian online, Note 18.

27 According to the findings in this report, the escalated growth of renewable energy technologies in the recent years has been driven by an increasing number of policies creating a supportive environment for renewable energies by helping to overcome central policy barriers such as those related to existing industries, market failures or lack of technical knowledge and capacity. 
published its Special Report on Renewable Energy Sources and Climate Change Mitigation (SRREN). This report emphasises the role of renewable energies in mitigating the impacts of climate change. Under the current climate change regime, South Africa as member of the so called Non-Annex I group (i.e. developing countries) is not bound to reduce its greenhouse gas emissions. Yet, at least some members of the Non-Annex I group will have to control and reduce emissions, as especially the rapid economic development in China and India over the last decade has shown. ${ }^{28}$ In this context the South African contributions to greenhouse gas emissions must also be taken into account. With regard to the total $\mathrm{CO}_{2}$ emissions in 2008, the Carbon Dioxide Information Analysis Centre, an organisation within the United States Department of Energy, ranks South Africa already as the $13^{\text {th }}$ largest emitter worldwide. ${ }^{29}$ Predominantly coal-based energy production is by far the largest single source of greenhouse gas emissions in South Africa, contributing about 89 per cent of the total emissions. ${ }^{30}$ The high carbon intensity of the South African electricity production is with an average of about $850 \mathrm{~g} \mathrm{CO} 2 / \mathrm{kWh}$ nearly twice as high as in the industrialised countries. ${ }^{31}$

Against this background the South African Government acknowledged that the country is one of the highest emitting Non-Annex I countries and introduced policy measures towards emissions reductions. ${ }^{32}$ Only recently, South African Government adopted a National Climate Change Response White Paper. ${ }^{33}$ This paper emphasises South Africa's vulnerability and exposition to climate change impacts. Beyond that it also recognizes that "South Africa is a relatively significant contributor to global climate change with significant GHG emission levels from its energy-intensive, fossil-fuel powered economy". ${ }^{34}$ Correspondingly, the White Paper provides for the South African government's climate change response policy aiming at a "long-term transition to a climate-resilient, equitable and internationally competitive lowercarbon economy and society". ${ }^{35}$ The paper envisages the implementation of strategic flagship programmes consisting of both adaptation as well as mitigation measures. These programmes include a Renewable Energy Flagship Programme which "is inclusive of a scaled-up renewable energy programme". ${ }^{36}$ The current South AfricanProcurement Programme can be regarded as a first practical step towards an enhanced deployment of renewable energy tech-

28 Oliver C Ruppel, Climate Change and Human Vulnerability in Africa, in: Oliver C Ruppel/ Katharina Ruppel-Schlichting (eds), Environmental Law and Policy in Namibia, Windhoek 2011, p. 315.

29 Ranking available under $<$ http://cdiac.ornl.gov/trends/emis/top2008.tot $>$ (accessed 24-01-2012).

30 Edson L Meyer/Kola O Odeku, note 8, p. 50.

31 Anna Pegels, Renewable energy in South Africa: Potentials, barriers and options for support, Energy Policy 38 (2010), p. 4946.

32 Edson L Meyer/ Kola O Odeku, note 8, p. 51.

33 The paper was formally published in mid-October under $<$ http://www.info.gov.za/view/DownloadFileAction?id=152942> (accessed 24-01-2012).

34 National Climate Change Response White Paper, $\mathrm{p} 8$.

35 National Climate Change Response White Paper, p 10.

36 National Climate Change Response White Paper, p 31. 
nologies. It can be fairly integrated into the envisaged flagship programme once this has been substantiated.

\section{Renewable energy promotion in light of socio-economic framework conditions}

South Africa - like other emerging markets - still features the numerous challenges of a developing country; social and economic development remains a key priority. In the energy sector, this becomes manifest in the need to further expand energy access and to secure energy prices affordable for all parts of society. However, South Africa's scope of action is also determined by the fact that the country is part of one of the regions which is mostly affected by climate change worldwide. Southern Africa already is a water-stressed region. Climate change will not only accelerate this problem significantly but consequently have serious impacts on forestry, agriculture, biodiversity, food security and human health, thus becoming a threat for socio-economic development in general. ${ }^{37}$ For this reason it is necessary for countries in Southern Africa to seriously address and plan for climate change. In this context South Africa is in a specific position. While all other countries in Southern Africa only marginally contribute to greenhouse gas emissions and will have to focus on adaptation measures, South Africa will need to also engage in mitigation measures given its significant contribution to greenhouse gas emissions nowadays.

Correspondingly, South African energy policy is influenced by determinants acting in different directions. The country still faces a need for enhanced energy access for considerable parts of the population and, at the same time, has to seriously reduce its greenhouse gas emissions. So far the South African energy market is arranged quasi-monopolistic around the country's abundant coal resources. In order to reduce emissions, this coal-dependency has to be reduced. Decoupling energy and greenhouse gas emissions is necessary to achieve both widespread energy use and decreasing emissions; this remains one of the major challenges for South African policy. ${ }^{38}$ As the country also features abundant renewable sources with perfect conditions in solar radiation and good wind regimes, the use of renewable energy offers a vision for a structural change. South African policy makers have recognised the importance of renewable energy promotion as early as in the 2003 White Paper. The development of largescale renewable energy supply has been regarded as a target to meet both the increasing demand in energy as well as growing environmental concerns about energy systems based on fossil fuels. ${ }^{39}$ It would also mean innovation for South Africa's industrial basis. However, South Africa also has to keep government expenditure and the affordability of electricity in mind. Thus, the reconciliation of renewable energy promotion with these elementary needs remains the major challenge.

37 Oliver C Ruppel, note 28, p. 309; Isaac Mapaure, Climate Change in Namibia: Projected Trends and Effects, in: Oliver C Ruppel/ Katharina Ruppel -Schlichting (eds), Environmental Law and Policy in Namibia, Windhoek 2011, p. 290.

38 Anna Pegels, note 31, p. 4946.

39 South African Department of Minerals and Energy, White Paper on Renewable Energy, 2003, p. 33. 


\section{Outlook}

Although the 2003 White Paper promulgated the diversification of energy supply and the necessity to promote renewable energies with an appropriate legal and regulatory framework quite early, the actions taken on the political level have not been successful so far. Eight years after the 2003 White Paper still no relevant renewable energy installations have been deployed yet. This is predominantly due to the fact that, in the past, policy has not been clear and concordant in introducing its support measures.

The new Procurement Programme can be the turning point in renewable energy promotion in South Africa; the instrument finally seems to have the necessary government support. Even if early experiences with bidding procedures have not proven to be successful, South Africa has the chance to learn from these experiences and adjust its regulatory conditions based on these lessons. With regard to government expenditure and the affordability of electricity, a competitive bidding process might be more promising to keep the prices down than a feed-in tariff. ${ }^{40}$ However, the current Procurement Programme can only be the first step. For the future renewable energy promotion policy in South Africa it will be necessary to provide a stringent regulatory framework, including, inter alia, rules on fair access to electricity grids and adapted building-codes. To be reliable and transparent for project developers, the regulatory framework will have to be documented and unanimously supported by government. Only authoritative documentation will have the potential to create a secure investor environment. The most adequate way to achieve a consistent regulatory framework seems to be the establishment of a promotion system by law. This would add weight to a political decision on a specific promotion system and contribute to transparency and foreseeability as major prerequisites for investment decisions in the renewable energy sector.

40 Harald Winkler, Renewable energy policy in South Africa: policy options for renewable electricity, Energy Policy 33 (2005) p. 34, also pointing out that after the bidding process it would remain a critical challenge to prevent collusion between suppliers to drive prices up. 